Article

\title{
Retrofit Planning for the Performance Gap: Results of a Workshop on Addressing Energy, Health and Comfort Needs in a Protected Building
}

\author{
Eugene Mohareb ${ }^{1} \mathbb{B}^{\mathbb{D}}$, Arman Hashemi ${ }^{2, *}$, Mehdi Shahrestani ${ }^{1}$ and Minna Sunikka-Blank ${ }^{3}$ \\ 1 School of the Built Environment, University of Reading, Reading RG6 6DF, UK; \\ e.mohareb@reading.ac.uk (E.M.); m.shahrestani@reading.ac.uk (M.S.) \\ 2 School of Environment and Technology, University of Brighton, Brighton BN2 4GJ, UK \\ 3 Department of Architecture, University of Cambridge, Cambridge CB2 1PX, UK; mms45@cam.ac.uk \\ * Correspondence: a.hashemi@brighton.ac.uk
}

Received: 30 June 2017; Accepted: 5 August 2017; Published: 10 August 2017

\begin{abstract}
Research on the performance gap suggests that the actual energy consumption in buildings can be twice as much as expected from modelled estimates. Energy models rely on predictive indicators and assumptions that are usually done at the design stage, without acknowledging behavioral patterns of actual users, amongst other uncertain elements. Moreover, in the context of the performance gap, it is evident that energy efficiency is overemphasized while other key issues such as health and comfort of occupants associated with indoor air quality, noise levels etc., have been less stressed and discussed. This paper discusses physical measurements of indoor temperature in a case study building at the University of Cambridge and reports findings of a workshop with researchers, building professionals and graduate students working on environmental performance in the built environment. The workshop addressed research issues related to energy, comfort and health (couched in terms of thermal performance), used as a means to understand the complexities of and trade-off between different aspects of sustainable buildings. Retrofit measures were suggested while considering how to balance energy and comfort needs, with some these measures being modelled to determine their efficacy. This research concludes with a reflection on how to implement these retrofit measures in a manner that addresses the performance gap.
\end{abstract}

Keywords: performance gap; building simulation; energy retrofit; health; thermal comfort; listed buildings

\section{Introduction}

Buildings contributed to a substantial share of total UK energy demand in 2015, with domestic and non-domestic buildings making up $43 \%$ of the all energy consumption [1]. Additionally, they accounted for $18 \%$ of the UK's greenhouse gas (GHG) emissions in 2015 , with $75 \%$ of this share attributable to residences, $15 \%$ to commercial buildings and $10 \%$ to public sector buildings [2]. In particular, space heating was the largest energy end use, estimated to contribute up to $60 \%$ of total demand in households (2011) and 45\% in commercial buildings (2009) [3,4]. The successful long-term reduction of energy demand and related GHG emissions will require that high-performance buildings replace the existing energy-intensive building stock [5]. However, many modern high-performance building projects have achieved levels of energy performance that do not match up with projections modelled during their design. This has come to be referred to as the "performance gap", which is a product of a number of technical and behavioral factors, described below.

The misalignment with design estimates and actual energy performance has been uncovered through an increase in the use of post-occupancy evaluation, motivated by the surge in interest in 
certification of high-performance buildings, as well as government regulations mandating energy modeling. However, a prominent early application of post-occupancy evaluations was in the UK PROBE study of commercial buildings, which found energy performance was generally higher than anticipated [6]. The performance gap has appeared in various building end-use types and with a range of severity. A recent review found post-occupancy energy demand exceeded modelled values by $34 \%$ with a standard deviation of $55 \%$ for 64 non-domestic projects studied [7]. One case study office building assessed by the Carbon Trust [8] demonstrated a nearly five-fold increase in energy demand relative to the energy performance certificate estimate. Even in Carbon Trust case studies in which more detailed modeling was completed, there was a $16 \%$ increase in actual demand relative to modeled results, suggesting the challenge of accurate modeling and accurate prediction of user behavior. While performance occasionally improves upon predicted values, the Carbon Trust estimates that $75 \%$ of the variances from predicted energy demand are instances where energy demand was higher than design specifications.

High-performance domestic buildings face similar issues in matching design specifications of energy demand. The Energy Saving Trust [9] found that insulation measures in over 1500 UK domestic homes studied achieved an energy demand that was 50\% less than what was expected, on average. Calì and others [10] examined a sample of recently-refurbished German multi-unit residential buildings and performance gap of up to $95 \%$ in the first year after retrofitting for one building. Further, Johnson et al. [11] state studies of new-build dwellings in the UK have demonstrated actual energy performance that were more than double predicted values.

This performance gap is not unique to the UK construction; a US analysis of Leadership in Energy and Environmental Design (LEED) certified buildings found an equal number of buildings performed worse than estimated versus those that performed better-indeed, some of these high performance buildings had greater energy demands than the energy code baseline [12]. Similar underperformance has also been observed in New York City office buildings, with LEED-accredited office buildings often having higher energy use intensities than conventional office buildings [13].

A performance gap fundamentally implies higher energy consumption (and associated costs) than the occupant will have anticipated. In one case studied by the Carbon Trust [8], an additional $£ 10 / \mathrm{m}^{2}$ in unanticipated annual operating energy costs was observed by occupants in a particularly poor performing building. In pay-as-you-save energy retrofit schemes, the underperformance can be a burden on either the energy performance contractor or the building owner or occupant; where the realized savings do not match those that had been budgeted for, longer payback periods can result, as well as added costs and the potential for contractual disputes [7].

Research into the causes and mitigating factors of the performance gap is ongoing and points to complexity in the determinants of post-occupants energy demand. For example, one factor that is commonly pointed to as a significant uncertainty in energy modelling (and, hence a contributor to the performance gap) is user occupancy $[14,15]$; given its variability, stochastic approaches have been proposed for its estimation, with some success (examples include Fritsch et al. [16] and Wang et al. [14]). However, Ahn and others [15] demonstrate that stochastic methods are not representative of patterns of building are more random (e.g., such as libraries or laboratories), and demonstrate a "random walk" approach to estimating the occupancies of these types of buildings. Meanwhile, occupancy is just one of many variables in energy models, and error in estimating these variables is in itself just one of the many possible causes of the performance gap [17].

It is in this context that this paper aims to investigate the mitigation of the performance gap of a case study building at the University of Cambridge. This case study was assessed at a workshop focused on the performance gap issue, in which consideration of the performance of new and existing University buildings were discussed in an attempt to explain their shortcomings. The workshop activities are summarized, including a discussion of measures that were proposed to address the poor performance of a case study building. This is followed by a building simulation exercise that uses thermal comfort and health concerns associated with overheating as a focal point for the 
analysis of potential retrofit measures proposed in the workshop. This research then concludes with a discussion of how to realize the modeled energy performance associated with the proposed measures, towards reducing the performance gap in our case study building.

\section{Materials and Methods}

This research is comprised of three principle components; first, characterization of an underperforming building on the University of Cambridge's campus, including physical measurements; second, the workshop was held to analyze the building's performance and develop ideas for addressing the performance gap identified; and third, building energy modelling was conducted to assess selected measures, along with reflection on how this could be executed to reduce a further performance gap. Comfort and health concerns in this case study focuses on implications of overheating, which will be described in greater below. In this context, health is used to refer to concerns associated with overheating; while thermal comfort and indoor air quality both factor into considerations of health, assessments of indoor air quality are not included in the scope of inquiry in this research.

\subsection{The Case Study Building}

The selected case study was the Faculty of History in Cambridge (Figure 1). The design of James Stirling was selected based on an architectural competition in 1962. From the beginning, there were concerns about the building's environmental performance "the building would be subject to solar heat to a fairly large extent" (EMBS files 1963). The building was funded by the Universities Grants Committee (UGC), which meant that the funds had to be spent within a certain time frame and there was pressure to reduce the number of design iterations. The project was well funded; the contract price was $£ 104 / \mathrm{m}^{2}$ which amounts to $£ 2440 / \mathrm{m}^{2}$ at current prices. The design accommodates the history faculty, with an L-shaped stacked block of 6 levels enclosing a large fan-shaped glazed central space that houses the library. Early in construction, a poor relationship was reported amongst all parties, along with time/cost overruns and leaks were noted during the handover of the building. Due to neighbors' complaints an adjustment and reorientation of the building was made. After two decades of contending with construction and thermal comfort issues, demolition was considered in 1985 but the building was conserved and "grade II" listed in 2000.

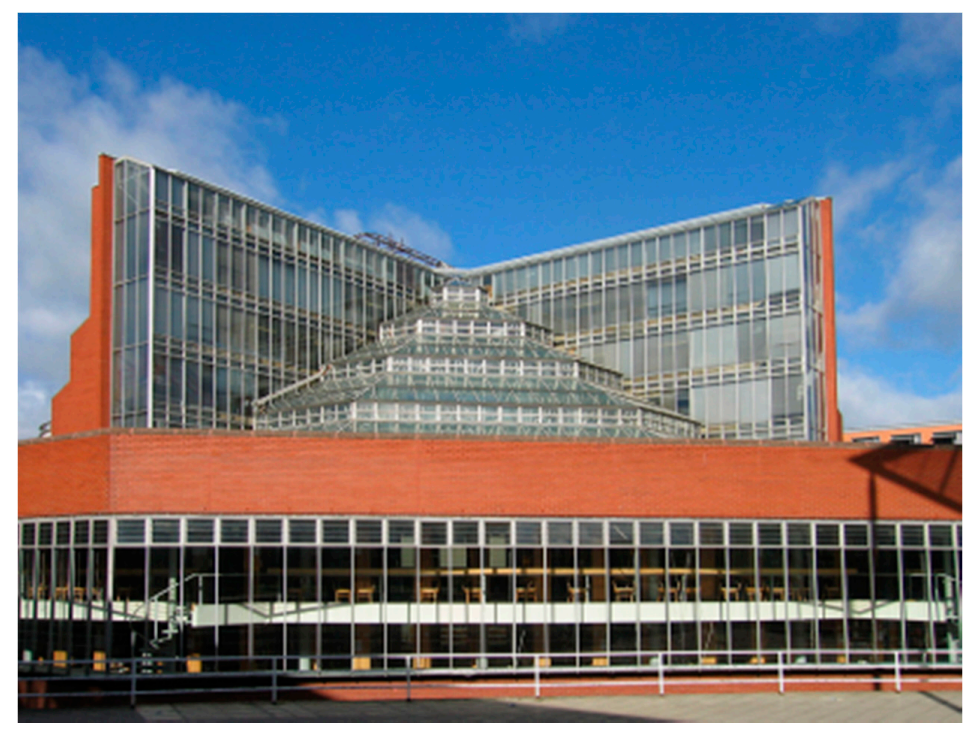

Figure 1. Faculty of History.

The main reason for the poor thermal comfort and high energy use is that $75 \%$ of the envelope above the plinth is standard industrial glazing, along with the giant stepped-pyramid skylight of the 
library (Figure 2). The glazed, double-skin roof in the library was meant to acts as a light diffusing layer where the inner layer was obscured to prevent glare and to give shadowless light in the reading area. This was also designed to insulate the cavity between the two skins so that all the louvres in the vertical steps would be closed in winter and opened in the summer to enable ventilation through the stack effect. Artificial light sources in the cavity and the roof provide an 'overhead spectacle'; however, the library space and office spaces are prone to overheating in summer (and to draught in winter). The noisy extraction fans in the library were never used and small air-conditioning units have been placed in the administrative corridors. Offices have draughty glass louvres for ventilation, along with secondary glazing and venetian blinds that have been installed during later renovations. It was predicted (somewhat dismissively) as early as 1968 that "controls will be fouled up through mismanagement by the humanities-oriented occupants who are below the average in mechanical literacy and competence, while the occupants will take verbal revenge on the architects-whereas revenge should be on UGC and their budgets that are too 'skimpy' to permit decent environmental installations or idiot-proof control systems" [18].

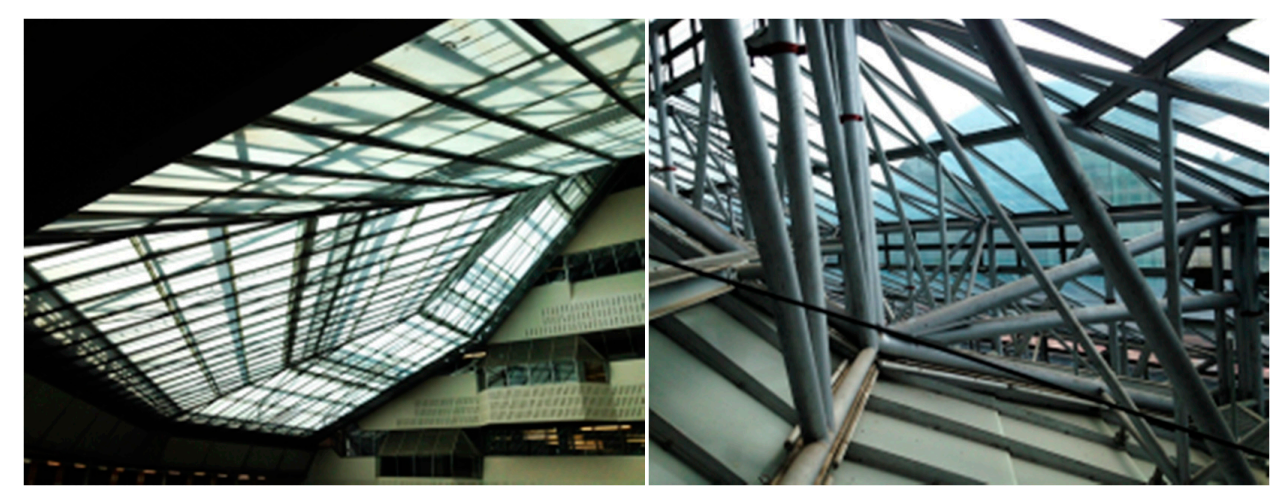

Figure 2. Glazed, double-skin roof of the library from inside the library (left) and inside the cavity (right).

The building received mixed reviews from the beginning. Brogan (1968) accused Stirling of 'complete disdain' for the users of their buildings and being "not so much undemocratic as anti-democratic: structural fascists". On the other hand, Banham, an recognized architectural critique in Britain, commented in Architectural Review (1968) that "the result, respectful to Cambridge at a more fundamental level of what Cambridge actually does, presents a startling critique of buildings that have tried to be respectful to Cambridge at the superficial level ... the sad things is that Cambridge opinion will eventually accept it as part of the 'Cambridge traditions' and then no one will have the guts to pull it down when the useful life for which it was designed has come to an end". Information on energy consumption in the University of Cambridge's buildings is provided for further context in Appendix A.

\subsection{Physical Measurement}

Physical measurements were carried out during February-August 2013 to evaluate indoor conditions and thermal comfort as well as the energy consumption in the case study building. Data loggers (Tinytag Ultra 2 DBT) (Specifications can be found at http:/ / gemini2.assets.d3r.com/ pdfs/original/1546-tgu-4017.pdf (accessed on 25 July 2017)) were installed on five different floors of the building to assess the conditions in various areas including in the main library, as well as corridors and office buildings. Measurements were taken every $30 \mathrm{~min}$ and locations of loggers are presented in Figure A2, Appendix B. This provides a quantitative assessment of the current state of energy performance and thermal comfort. 


\subsection{The Workshop}

A workshop was organized in 2015 to study energy, health and comfort needs in this case study, through a continuation of European Union Marie Curie FP7 project 'Uni-metrics' on sustainable campuses. The workshop mainly aimed to (a) develop a common understanding of research problems in energy efficiency, comfort and health in buildings in light of the performance gap; (b) identify knowledge gaps; and (c) gain an understanding from research projects that have addressed performance gap, comfort and health in buildings. The participants were provided with the above information on the current performance of building from the physical measurements. The participants also visited the case study building and spoke with occupants and facilities mangers to identify and evaluate the current conditions, as well as the problems of the building. Workshop attendees included staff, postgraduate students, and postdoctoral researchers from the European and North American Universities, including the University of Cambridge, Politecnico di Torino, University College London, and Pennsylvania State University, as well as private sector participants from building energy services firms.

Three themes were identified as the core subjects that needed to be investigated while developing solutions:

1. Energy (e.g., lighting, equipment, building envelope, renewable energy)

2. Architecture (e.g., interior/exterior, extension, partitions, retrofit, demolition)

3. Comfort and Health (e.g., thermal comfort, indoor air quality, noise, glare, ventilation).

\subsection{Modelling of Workshop Interventions}

A final component of this study involves an analysis of selected passive design retrofit strategies that were suggested in the workshop, including natural ventilation and internal shading. These are investigated to assess how well they could reduce the risk of overheating and address the outstanding performance gap in this protected building. The irony of further building energy modeling in response to performance issues could indeed lead to a future performance gap is not lost on the authors, and a reflection of measures that could be taken to address this are discussed, informed primarily by literature sources.

\section{Modeling Assumptions}

Dynamic Thermal Simulations were conducted to assess the conditions in the case study building using TRNSYS simulation package [19]. TRNSYS is one of the most appropriate tools for building thermal performance analysis. In addition, in terms of software validation, TRNSYS is one of the listed simulation programs in the Building Energy Software Tools Directory of the US Department of Energy (DoE) and International Energy Agency (IEA) [20]. Hence, the latest release of the TRNSYS simulation package (Version 17, Solar Energy Laboratory, Univ. of Wisconsin, Madison, WI, USA) is selected to assess the energy performance of the BIPV system in this study. It should be noted that in this numerical modeling, weather conditions are considered based on the Meteonorm database [21].

The thermal performance assessment is carried out through numerical modeling of the sixth floor (Figure 3) over a six-month period from May to September. The sixth floor was selected as it was the location in which the greatest degree of thermal discomfort had been observed through recent monitoring. The occupancy profile was considered as 8:00-18:00 Monday-Friday. Windows were assumed to be open when temperature of the zones reached $25-26^{\circ} \mathrm{C}$. Table 1 summarizes some of the further assumptions used in the simulations. 


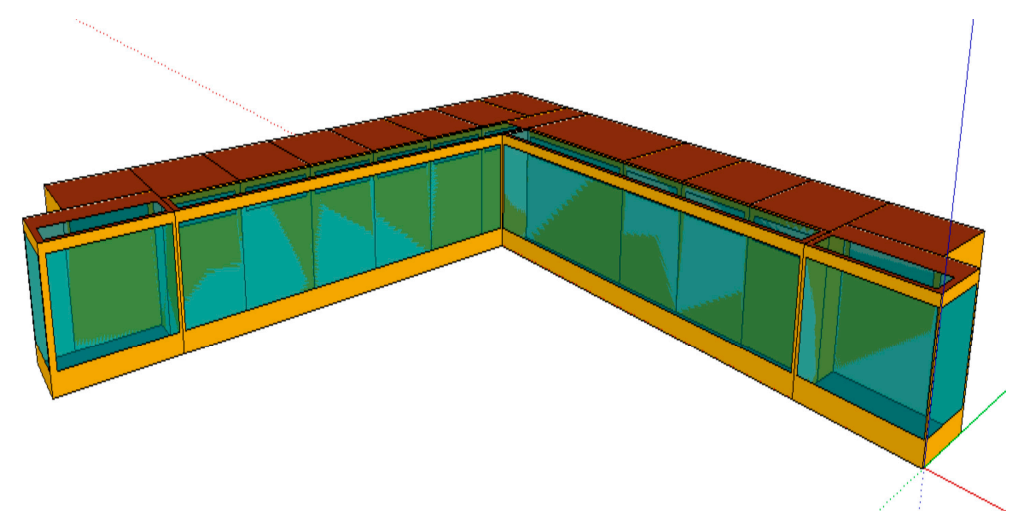

Figure 3. 3D model of the sixth floor.

Table 1. Simulation assumptions.

\begin{tabular}{ccc}
\hline Parameter & Unit & Value \\
\hline Thermal conductance (U-value) & & \\
External wall & $\mathrm{W} / \mathrm{m}^{2}-{ }^{\circ} \mathrm{C}$ & 0.28 \\
Roof & & 0.18 \\
Window & $\mathrm{m}^{2} /$ person & 1.08 \\
Occupancy density & $\mathrm{W} / \mathrm{m}^{2}$ & $13-15$ \\
Lighting power density & $\mathrm{W} /$ person & 200 \\
Electrical equipment loads & liters $/ \mathrm{s}$-person & 10 \\
Ventilation rate & \\
\hline
\end{tabular}

An adaptive approach was considered for the thermal comfort assessments. According to CEN standard BS EN 15251 (BSI 2007), a comfortable temperature in naturally ventilated buildings can be predicted using Equation (1), where $\mathrm{T}_{\text {comf }}=$ the maximum comfortable temperature $\left({ }^{\circ} \mathrm{C}\right)$; $\mathrm{T}_{\mathrm{rm}}=$ the running mean temperature for today weighted with higher influence of recent days [22] $\left({ }^{\circ} \mathrm{C}\right)$. $\mathrm{T}_{\mathrm{rm}}$ can also be calculated using Equation (2) where $\mathrm{T}_{\text {ed-1 }}=$ the daily mean external temperature for the previous day $\left({ }^{\circ} \mathrm{C}\right) ; \mathrm{T}_{\mathrm{ed}-2}=$ the daily mean external temperature for the day before $\left({ }^{\circ} \mathrm{C}\right)$ and so on; $\alpha=$ constant; reference [22] suggest using $\alpha=0.8$.

$$
\begin{gathered}
\mathrm{T}_{\text {comf }}=0.33 \mathrm{~T}_{\mathrm{rm}}+18.8+3\left(\text { where } \mathrm{T}_{\mathrm{rm}}>10{ }^{\circ} \mathrm{C}\right) \\
\mathrm{T}_{\mathrm{rm}}=(1-\alpha) \cdot\left\{\mathrm{T}_{\text {ed-1 }}+\alpha . \mathrm{T}_{\text {ed-2 }}+\alpha^{2} . \mathrm{T}_{\text {ed-3 }} \ldots\right\}
\end{gathered}
$$

The risk of overheating in an adaptive approach is assessed based on the frequency and severity of overheating using three criteria, as defined in the Chartered Institute of Building Services Engineers (CIBSE) Technical Memorandum number 52 [23]. A building is assumed to be overheated if it fails any two of the three assessment criteria. Table 2 summarises the thermal comfort assessment criteria.

Table 2. Thermal comfort assessment criteria.

\begin{tabular}{ccc}
\hline & Assessment Criteria & Acceptable Deviation \\
\hline Criterion 1 & $\begin{array}{c}\text { Frequency of occupied hours when operative temperature is } \\
\text { greater than maximum comfortable temperature }\end{array}$ & Up to 3\% of occupied hours \\
\hline Criterion 2 & $\begin{array}{c}\text { Severity of thermal discomfort by calculation of number of day } \\
\text { degree hours of warm period }>6^{\circ} \mathrm{h} \text { a day }\end{array}$ & 0 day \\
\hline Criterion 3 & $\begin{array}{c}\text { Severity of thermal discomfort by reporting } \\
\text { Number of hours in which } \Delta \mathrm{T}>4^{\circ} \mathrm{K}(\Delta \mathrm{T}=\text { Toperative }-\mathrm{Tmax}, \\
\text { rounded to the nearest whole degree })\end{array}$ & $0 \mathrm{~h}$ \\
\hline
\end{tabular}




\section{Results}

\subsection{Observations of Case Study Current Performance}

Table 3 shows the annual electricity consumption of the case study building between 2005 and 2014. According to the results, the annual energy consumption over the period between 2005 and 2014 has remained nearly constant, averaging $216,549 \mathrm{kWh}$ per annum, or $49.3 \mathrm{kWh} / \mathrm{m}^{2}$ (for a total floor area of $4393 \mathrm{~m}^{2}$ ).

Table 3. Electricity Consumption in the Faculty of History Building, University of Cambridge, 2005-2014 (financial years starting in April).

\begin{tabular}{cccccc}
\hline Year & $\mathbf{2 0 0 5 - 2 0 0 6}$ & $\mathbf{2 0 0 6 - 2 0 0 7}$ & $\mathbf{2 0 0 7 - 2 0 0 8}$ & $\mathbf{2 0 0 8 - 2 0 0 9}$ & $\mathbf{2 0 0 9 - 2 0 1 0}$ \\
\hline $\begin{array}{c}\text { Annual energy } \\
\text { consumption }(\mathrm{kWh})\end{array}$ & 223,287 & 222,608 & 226,760 & 214,548 & 222,726 \\
\hline Year & $\mathbf{2 0 1 0 - 2 0 1 1}$ & $\mathbf{2 0 1 1 - 2 0 1 2}$ & $\mathbf{2 0 1 2 - 2 0 1 3}$ & $\mathbf{2 0 1 3 - 2 0 1 4}$ & - \\
\hline $\begin{array}{c}\text { Annual energy } \\
\text { consumption }(\mathrm{kWh})\end{array}$ & 209,891 & 215,046 & 212,868 & 201,278 & - \\
\hline
\end{tabular}

Figures 4 and 5 show the internal temperatures and relative humanity as well as the external temperatures during one year in different areas of the building. According to the results, the building has been thermally uncomfortable in almost all areas (per the definition provided in Table 2). The internal temperature in many areas has reached $35^{\circ} \mathrm{C}$; the indoor temperature in the rooms/offices between July and August has frequently been over $30^{\circ} \mathrm{C}$. The temperature in the main library on the ground floor has also fluctuated greatly and in many cases has exceeded $30^{\circ} \mathrm{C}$. Meanwhile, CIBSE Guide A 2015 recommends average summer operative temperatures of $24-25^{\circ} \mathrm{C}$ for libraries and 22-25 ${ }^{\circ} \mathrm{C}$ offices, respectively [23]. This presents serious comfort and health challenges for occupants.
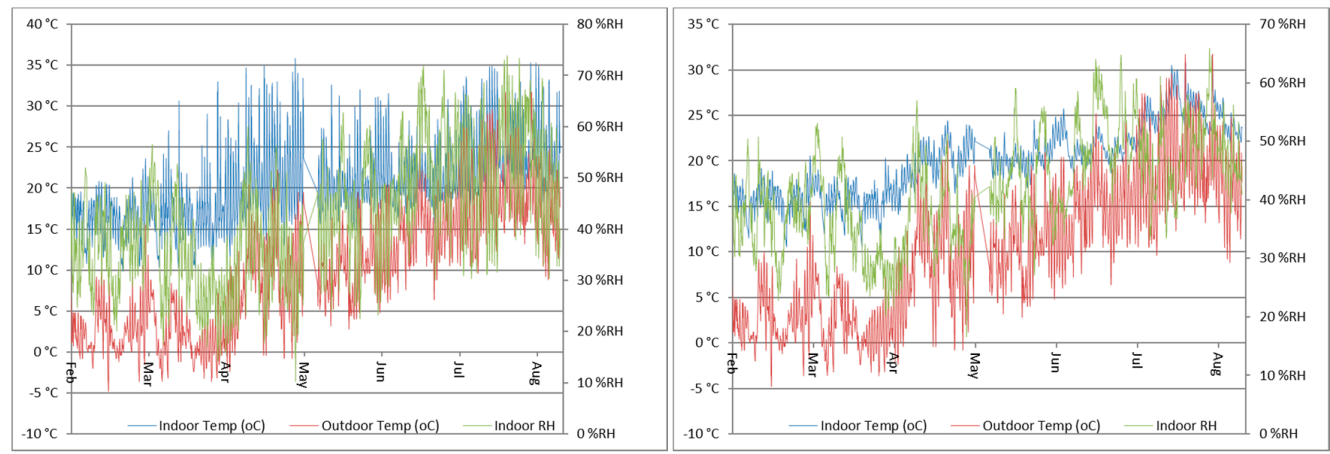

Figure 4. Ground Floor Library (Left); 1st Floor Library (Right) (University of Cambridge).
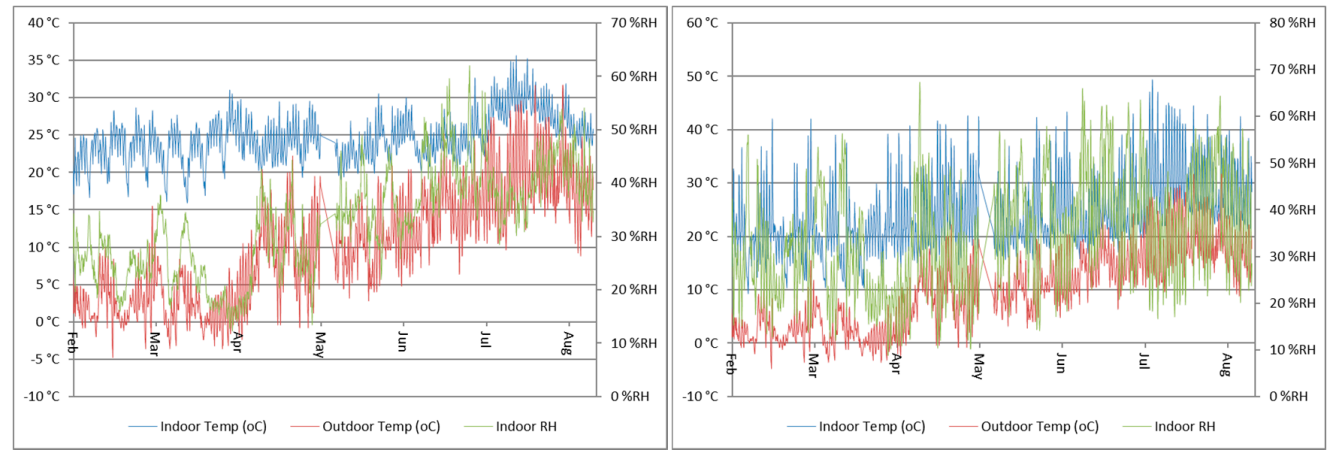

Figure 5. Room on the 4th floor (Left); 6th Floor Corridor (Right) (University of Cambridge). 
The situation has been considerably worse in the corridors on the 6th floor (Figure 6) as the temperature has reached nearly $50{ }^{\circ} \mathrm{C}$ which is an indicator of severe, and potentially dangerous, thermal comfort conditions for the occupants; the UK Health and Safety Executive and the Chartered Institute of Building Services Engineers recommend maximum indoor temperatures for comfort of 30 and $25^{\circ} \mathrm{C}$, respectively [24]. Extremely high indoor temperatures in the building necessitated the use of air conditioning units, particularly on the higher floors. According to Figure 4, occupants also experience extremely low temperatures (between $10{ }^{\circ} \mathrm{C}$ and $15^{\circ} \mathrm{C}$ ) during winter. Such conditions indicate high heating and cooling requirements in the case study building during both winter and summer. Yet, considering benchmarks, the average electricity consumption of $49.5 \mathrm{kWh} / \mathrm{m}^{2}$ is rather low. A possible explanation for this may be the seasonal use of the building by the occupants.

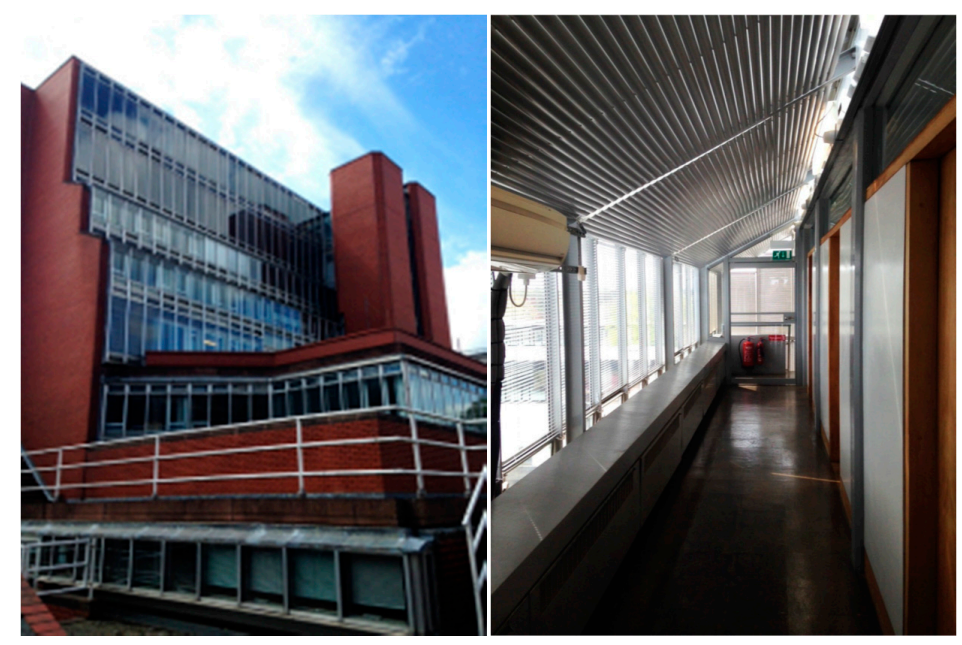

Figure 6. Excessive glazing and solar heat gain contribute to overheating.

\subsection{Summary of Workshoip Proporals and Findings}

Two randomly selected groups were formed to analyze the performance concerns of the building and propose measures. Group A followed an approach divided in three sections: (a) identification of problems; (b) proposed energy efficiency measures; (c) cost/time/benefit assessment of proposed measures. After the walkthrough inside the case study building, the group discussed the elements that could lead into inefficient energy use. The following issues were raised:

- Building users unable to understand and operate the building's passive features (glass louvre ventilators, venetian blinds).

- Air conditioners placed in corridors as an additional way of heating/cooling indicating the inefficiency of the existing heating/cooling system.

- Lights left on in corridors and the library during periods of low occupancy.

- Window blinds that were meant to prevent overheating obstructed daylighting potential.

- Extraction fans of the existing mechanical ventilation system deactivated due to noise.

In terms of the proposed efficiency measures, the group emphasized the need to respect the building's aesthetic quality through discrete material interventions while focusing on educating the users on the proper use of its passive features and systems. The following efficiency measures were proposed as solutions to improve the energy performance of the building:

- Fritted glass for the outer layer of the double-glass envelope that assists with the building's natural ventilation scheme, daylighting and weather shielding. The pattern of the fritted glass will be specially designed for the building to enhance its aesthetic value and diffuse light as it enters the building, reducing glare as well as solar gain. 
- Behavioral nudging from an interactive 'building wizard' accessible through the building's IT systems.

- Building user guide to be provided during staff inductions and along with guidance on the proper use of the building's passive/active systems and their controls.

- Improved Heating Ventilation and Air Conditioning systems with heat recovery system to replace the existing noisy ventilation system.

- $\quad P V$ panels in southern-facing façade to provide electricity for light-emitting diode (LED) lighting.

- Reprogramming of movement lighting sensors in shorter time intervals.

- Carpeting the library for noise reduction.

- Thermal buffer zone in the entrance to prevent heat loss.

The practical aspects related to the implementation of the proposed interventions (cost, benefit, timeframe) were presented in a comparative graph. The different measures were plotted based on their cost (high, medium, low), the timeframe of their implementation and their perceived impact on energy efficiency and comfort (small, medium, and high) as assessed by the attendees (Figure 7).

\section{Proposed interventions}

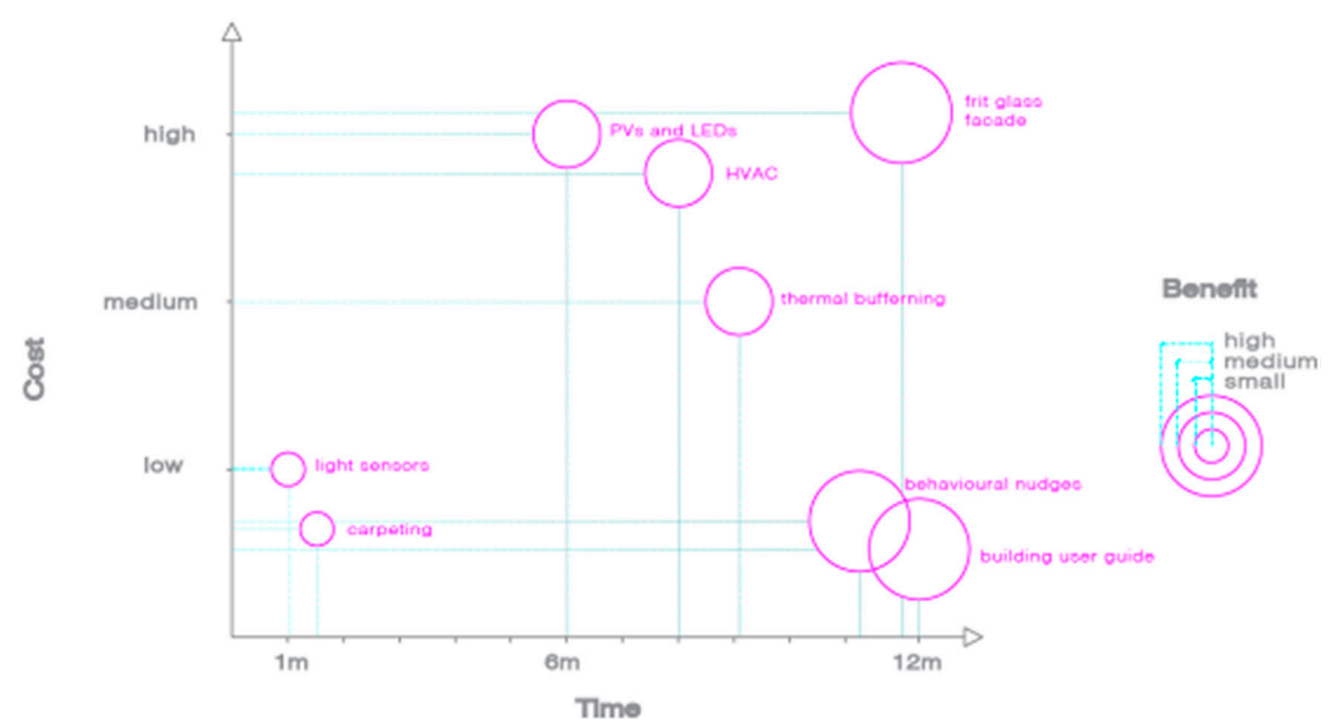

Figure 7. Proposed interventions for the refurbishment of the History Faculty at the University of Cambridge based on the cost, implementation timeframe and benefit.

In terms of comfort and energy efficiency, the replacement of the outer layer of the building's glass envelope with fritted glass and the behavioral nudges were the interventions with a higher expected impact. The new façade intends to give a creative and delicate aesthetic touch, enhancing the identity and popularity of the building however, this is anticipated to be a costly intervention. The interactive 'building wizard' would be less costly but needs constant update and monitoring. The case where the two measures are combined is seen as the optimal intervention in the existing context.

Group B explored three discrete options for a fundamental shift in the building's operation. These options focused on changes in end use, energy demand/supply systems, and building services systems. The discretization of these options was understood to be purely theoretical, as components of all three options would likely be considered in any planned building upgrade. However, for the sake of the workshop exercise, it was pursued in the interest of a deeper understanding of the value of each approach. 
The options were assessed using four main criteria, which included six sub criteria: cost (capital and operating), time required for implementation, user impacts (during transformation and post transformation), and aesthetic impacts (heritage and public perception). While the intention of most of these criteria are self-evident, the aesthetic impacts require further explanation. The "heritage" component relates to the preservation of the original architectural value of the building, especially in conforming to its Grade II listed building status. The "public perception" aesthetic feature was based on the assumption that the general public does not view the current modernist design favorably and would welcome an upgrading of the exterior of the building. A summary of the evaluation of the three options is provided in Table 4 .

Table 4. Proposed changes to the Faculty of History building to address its poor thermal performance.

\begin{tabular}{|c|c|c|c|c|c|c|c|c|}
\hline \multirow{2}{*}{ Proposed Change } & \multicolumn{2}{|c|}{ Cost } & \multirow{2}{*}{ Time } & \multicolumn{2}{|c|}{ User Impact } & \multicolumn{2}{|c|}{ Aesthetic } & \multirow{2}{*}{ Sum * } \\
\hline & Capital Cost & Operating Cost & & Mid-Transform & Post-Transform & Heritage & Public Perception & \\
\hline User & 4 & 3 & 4 & 1 & 4 & 3 & 2 & 21 \\
\hline $\begin{array}{l}\text { Energy Demand } \\
\text { Supply }\end{array}$ & 1 & 4 & 1 & 2 & 4 & 2 & 4 & 18 \\
\hline Building Services & 2 & 2 & 2 & 3 & 2 & 4 & 2 & 17 \\
\hline
\end{tabular}

The first option for transforming the building assessed the problems surrounding the building's primary end uses as a library and for faculty office space. Given the problems with overheating in the summer and difficulties maintaining a sufficiently warm temperature in the winter, the conversion of the building to a more compatible end-use, such as botanical research lab, seemed worthy of consideration. The ample solar access and the inhospitableness for humans lead to this suggestion. This would also be a relatively low cost solution, requiring an exchange of users from the poorly conditioned Sainsbury Lab for botanical studies, for example. The time requirement would likely be low, and the heritage value could be retained. Mid-transformation impacts and public perceptions scored low, but it was projected that user satisfaction would be very high after the relocation.

The second option involved a substantial investment in low-carbon technologies and passive measures for the building. While the library's skylight structure would be retained, it would be covered with PV panels. The natural lighting would be reduced substantially and the interior of the glazing would be fitted with special LED panels (in essence, shading) that could be used to project images of the sky or any other suitable visuals that would be pleasing to the library occupants and other areas of the building. The PV panels would supply electricity to meet demand within the building, with any excess production being converted to heat for a borehole thermal energy storage network located on the building's present site (the Sedgwick site). The building envelope would also be upgraded to meet high performance standards and reduce heating/cooling demand, while allowing for greater natural ventilation, particularly in the office area.

This approach was deemed to require high up-front investment, be disruptive to occupants during the construction phase, take the greatest time to complete and negatively affect the heritage value of the building. The participants agreed that loss of the heritage aesthetic would be an increasingly unavoidable issue in meeting the necessary improvements of building stock performance towards the University's 2050 GHG reduction goals. The energy supply and demand improvements were expected to perform well in post-construction operating costs and user satisfaction, as well as public perception of its updated facade.

The final option suggested by the group was to improve the building services, focusing on automation and highly-sensitive occupant detection systems. This option envisioned automated building service controls, coupled with redesigned heating and ventilation systems that serviced zones on the scale of individual offices. These zones would be equipped with motion, $\mathrm{CO}_{2}$, and humidity sensors, with highly-structured user feedback systems, enabling fine-tuning of controls of the building services. This approach was projected to be costly in both construction and operation, with the latter 
requiring frequent servicing of the advanced control systems and heating/ventilation network. As well, while the installation of such a scheme might be less invasive to users during its installation, it was expected to require more work in keeping the user feedback system 'tuned' and take a long time to install. The heritage value of the building would be retained, but this approach would not improve public perception as no externally-visible upgrades would be included.

Ultimately the group felt that a focus on changing the end user would score the best if all criteria were weighted equally. However, the weighting of the criteria would depend on the goals of the University and physical/cost/user constraints. As well, each option had merits and a more integrated implementation of these could remedy the detriments of each of the others.

\subsection{Modelling of Selected Proposed Interventions}

After consideration of the various measures proposed by the three groups, a selection was made of those that would not contravene the building's protected status (and that could be practicably modeled). The focus was on the top floor of this building, where severe over heating issues have been observed to date. The selected measure included the application of internal shading and cross-ventilation, as proposed by Group B, in the "Energy Supply/Demand" proposed change.

The thermal perfomance of the model is assessed under 3 scenarios (as described in Table 5) and the distributuion of the air temperature under these scenarios are provided in Figures 8-13. Comparing the distribution of indoor air temperature under the second scenario (Figures 10 and 11), with the first scenario (Figures 8 and 9) shows that internal shading-blind does not contribute significantly to reducing the indoor air temperature in the period between May to September. However, cross ventilation through openings between corridors and offices (Figures 12 and 13) can significatly contribute to reduction of indoor air temperature up to $10{ }^{\circ} \mathrm{C}$ compared to the first scenario (Figure 2). It was found that under Scenario 3, thermal comfort thresholds were exceeded $5 \%$ of the time, an improvement to $96 \%$ and $94 \%$ of the time under scenarios 1 and 2, respectively.

Table 5. Studied scenarios.

\begin{tabular}{cc}
\hline Scenario & Description \\
\hline 1 & Base case-without cross ventilation and shading \\
2 & With internal shading (50\% Transparency) and without cross ventilation \\
3 & Cross ventilation by providing opening between offices and corridors but without shading \\
\hline
\end{tabular}

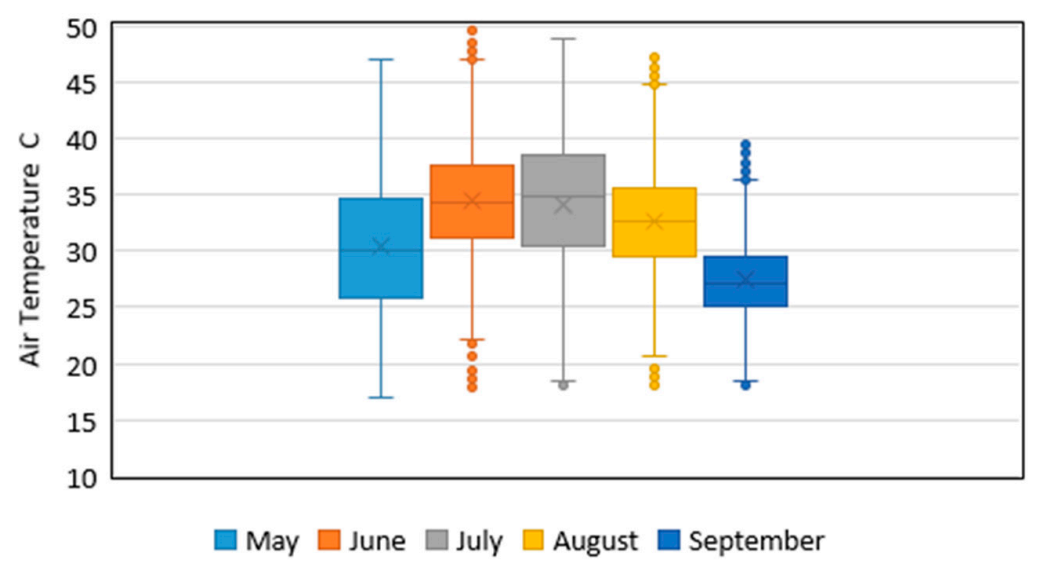

Figure 8. Distribution of air temperature in 6th floor without cross ventilation and without internal shading (scenario 1). 


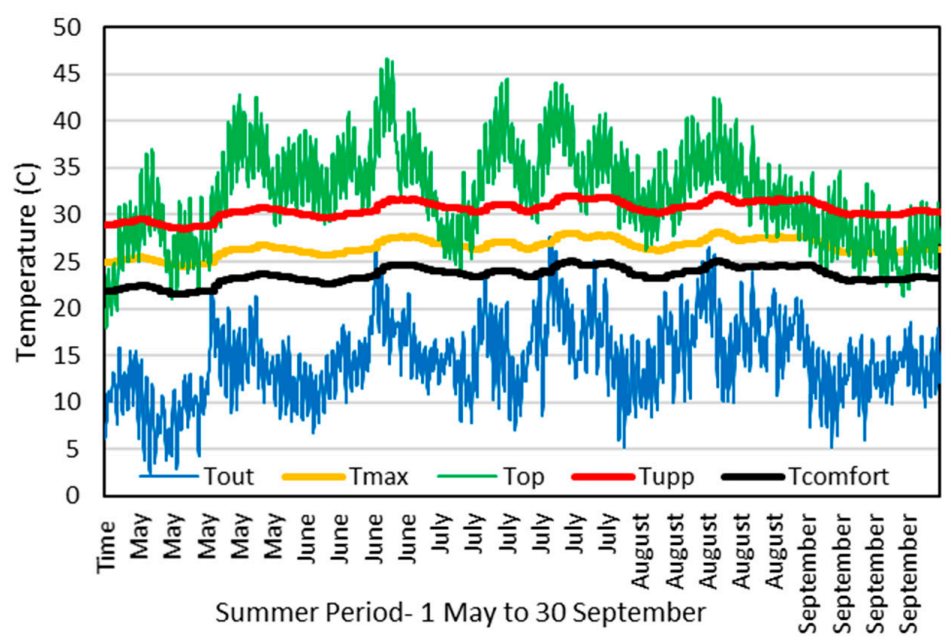

Figure 9. Distribution of indoor and outdoor air temperature, operative and comfort temperature in 6th floor considering cross ventilation (scenario 1).

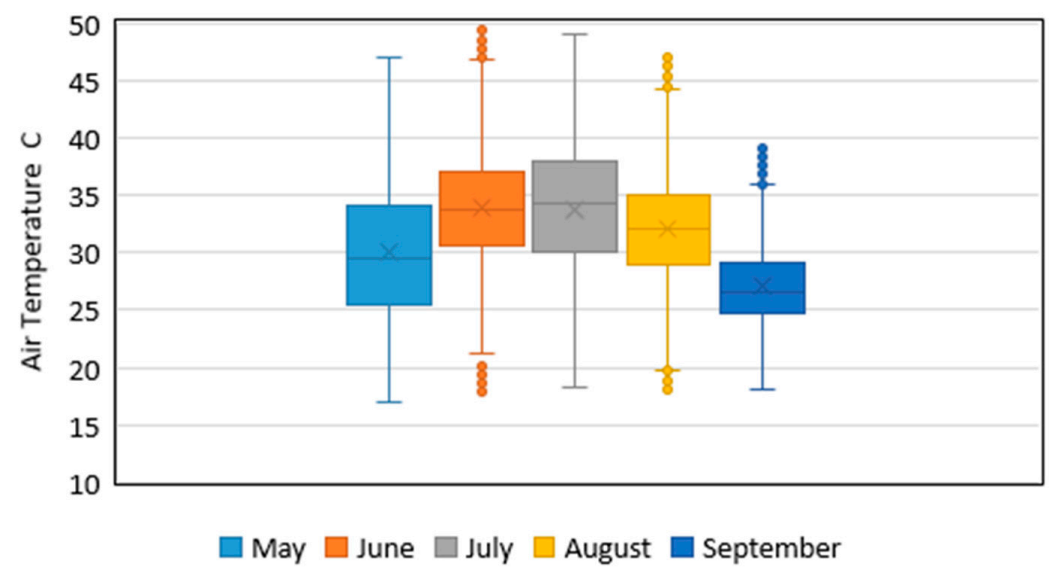

Figure 10. Distribution of air temperature in 6th floor without cross ventilation but with internal shading (scenario 2).

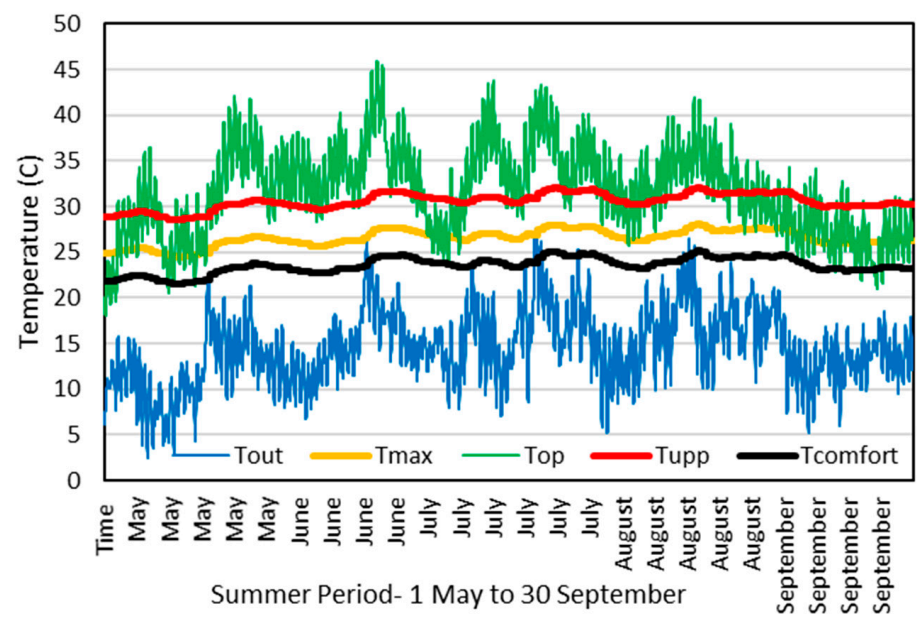

Figure 11. Distribution of indoor and outdoor air temperature, operative and comfort temperature in 6 th floor without cross ventilation but with internal shading (scenario 2). 


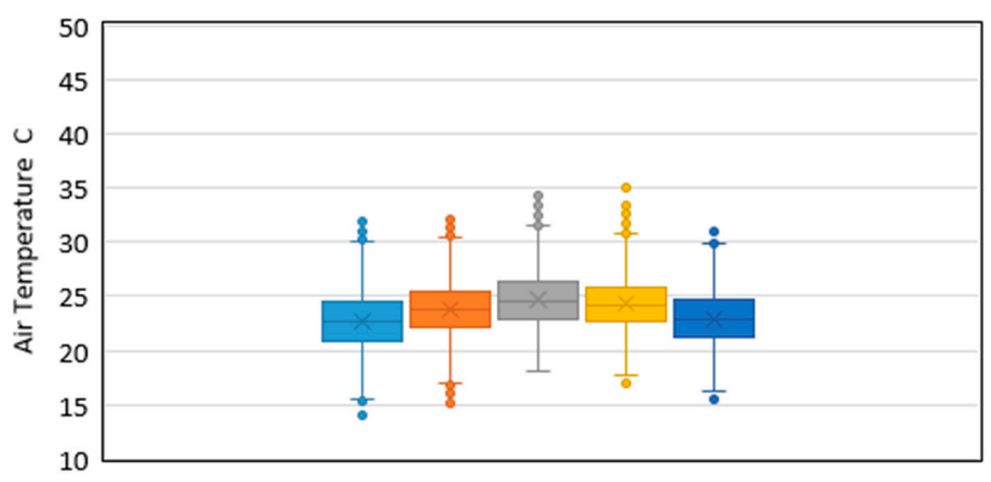

$\square$ May $\square$ June $\square$ July $\square$ August $\square$ September

Figure 12. Distribution of air temperature in 6th floor with considering cross ventilation (scenario 3).

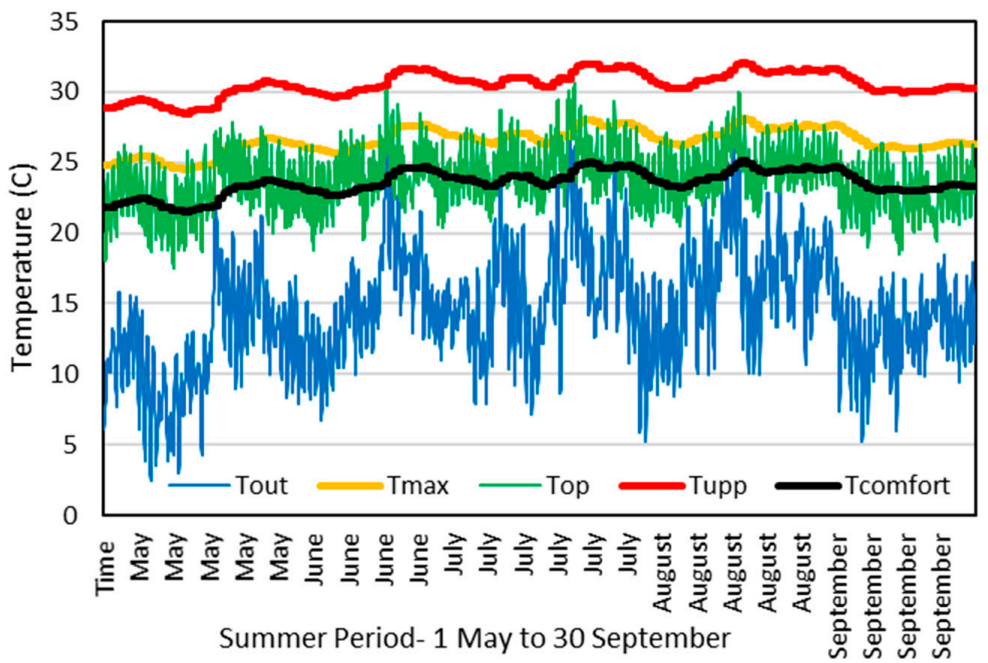

Figure 13. Distribution of indoor and outdoor air temperature, operative and comfort temperature in 6th floor considering cross ventilation (scenario 3).

As explained in the methodology section, in order to examine the thermal performance and the level of overheating under different scenarios, adaptive approach for thermal comfort analysis is adopted in this data analysis (CIBSE-TM 52, 2013). The outcome of the data analyses revealed the first two scenarios both failed in all three assessment criteria. However, the third scenario failed only the first criterion (by a relatively small amount) and was successful in fulfilling the requirements of next two criteria. In the third scenario, the percentage of the occupied hours when operative temperature was greater than maximum comfortable temperature reached to $4.9 \%$, which was just less than $2 \%$ more than what it should be. Figures 9, 11 and 13 demonstrate the distribution of outdoor air temperatures and indoor operative temperatures and the day-to-day values of maximum acceptable temperature and upper limit temperature together with comfort temperature in office zone in the north wing of the 6th floor.

\section{Discussion-Reflection on Performance Gap}

While our case study building was constructed in an era prior the arrival of sophisticated building energy simulation, it's (necessary) retrofit would occur in full consideration of how prevent deviations from the modelled performance. A number of technical deficiencies with respect to materials and installation can lead to diminished energy performance relative to modelled projections. These include: 
- Calculations or simplifications in modelling software are inconsistent or not checked/revised throughout the delivery process $[17,25,26]$.

- Higher efficiency materials and equipment can provide lower than expected performance $[17,27,28]$.

- Materials themselves may not be correctly installed per design specifications due to poor workmanship or inexperienced installers $[7,8,17,25]$.

- Buildings may not have been commissioned properly upon completion [8,17].

- Unregulated loads were not properly considered in the modelling process [8].

- Building designs themselves may be inherently flawed or design characteristics/goals poorly communicated [17].

- Poor communication between landlord (involved during the design process) and future occupants with respect to optimal building operation [29].

- Split incentive to fulfil energy performance between the building owner and tenant [29].

- Occupant behavior is markedly different from design estimates [10,17,30,31].

From this it follows that a number of factors need to be considered in addressing the thermal comfort challenges of the Faculty of History building as presented in the modeling exercise above. The complexity involved in building construction/retrofit and occupant behavior leads to a number of solutions that should be considered in effectively addressing the performance gap. In one German case study, Cali and others [10] found that through careful post-occupancy monitoring was able to remedy building performance issues related to technical issues with heat pumps and wide variation in occupant behavior. As well, Johnston et al. [11] were able to match expected energy demand through the careful quality control systems inherent in the PassivHaus certification process applied in their cases.

With respect to non-domestic buildings, Fedoruk and colleagues [32] suggest that, in the case of a showcase high-performance building on the University of British Columbia campus (Centre for Interactive Research on Sustainability), the performance gap was mostly attributable to issues outside of shortcomings in installed building components, and could have been reduced through building energy monitoring, improved integration between designers and builders (such as through design charrettes; [33]), and expanding current boundaries of energy analysis beyond the building itself. Robinson and collaborators [29] suggest a mandatory post-construction review (per BREEAM for New Construction's 2014 guidelines) and the 'soft landings' approach of continual post-occupancy communication between designers, owners, and occupants (directed by the CIBSE TM54) can contribute to a better match between anticipated and actual demand. From a legislative perspective, a regulatory framework to govern energy underperformance in buildings [7]. The authors also note the need for better monitoring for data collection, as well as more training that targets energy-related technical and communication skills in the building sector (construction and operation). Finally, Tuohy and Murphy [22] suggest that through reshaping the aims of Building Information Management to include actual building performance, providing ratings/awards based on actual performance, and the adoption of a more robust feedback systems in the design process, greater accountability can be realized with respect to actual energy demand.

\section{Conclusions}

This paper discussed potential retrofit options and performance gap using surveys and physical measurements in a case study building at the University of Cambridge. Overheating was identified as the major issue contributing to thermal discomfort and high-energy consumption in the case study building. Various design, operation, and management solutions (e.g., lighting and ventilation strategies, user controls, integrated renewable energy) were suggested by the workshop participants, as well as options such as complete change of use, to improve the conditions in the building.

When it comes to the performance gap, health and comfort should also be considered alongside the energy efficiency, as occupant behavior is a wildcard in energy models. Substantial savings could 
be achieved by fixing the technical problems, disaggregating consumption data and encouraging behavioral changes of end-users. Moreover, there exists a need to understand actual occupancy patterns, user requirements and social norms in the workplace in order to effectively address and improve both energy performance and comfort in future low-carbon buildings. In this respect, although technical deficiencies and information gaps play an important role, all stakeholders including clients, designers, builders, policy- and decision-makers need to understand potential trade-offs between aesthetic, comfort and energy values to close the gap.

Acknowledgments: The workshop was a continuation of EU Marie Curie FP7 project 'Uni-metrics' on sustainable campuses, organized by the GreenBRIDGE society and the Centre for Research in the Arts, Social Sciences, and Humanities. Special thanks to Arup, Faculty of History and the Environment and Energy Team at University of Cambridge for providing information and access to the case study building. Additionally, Tatiana Vakhitova, Dimitra Dantsiou, Hui Ben \& Tania Sharmin contributed to the planning and organization of the workshop.

Author Contributions: Eugene Mohareb, Arman Hashemi \& Minna Sunikka-Blank conceived, organized and conducted the workshop; Mehdi Shahrestani performed the simulations; Mehdi Shahrestani \& Arman Hashemi analyzed the data; all authors wrote the paper.

Conflicts of Interest: The authors declare no conflict of interest.

\section{Appendix A}

\section{Energy Use in University of Cambridge}

The University of Cambridge has a total floor area of $642,000 \mathrm{~m}^{2}$, over 330 buildings and 150 departments and institutions. The capital building program is $£ 60 \mathrm{M} / \mathrm{pa}$ (plus $£ 15 \mathrm{M}$ for equipment). There are 18,900 students and 9800 staff studying and working at the university. In 2013-2014 the University spent $£ 16$ million on energy. The University spends $£ 1825$ every hour (or around $£ 30$ every minute) on energy. Figure A1 shows the top 30 users of electricity in the campus (Environment and Energy Office 2016).

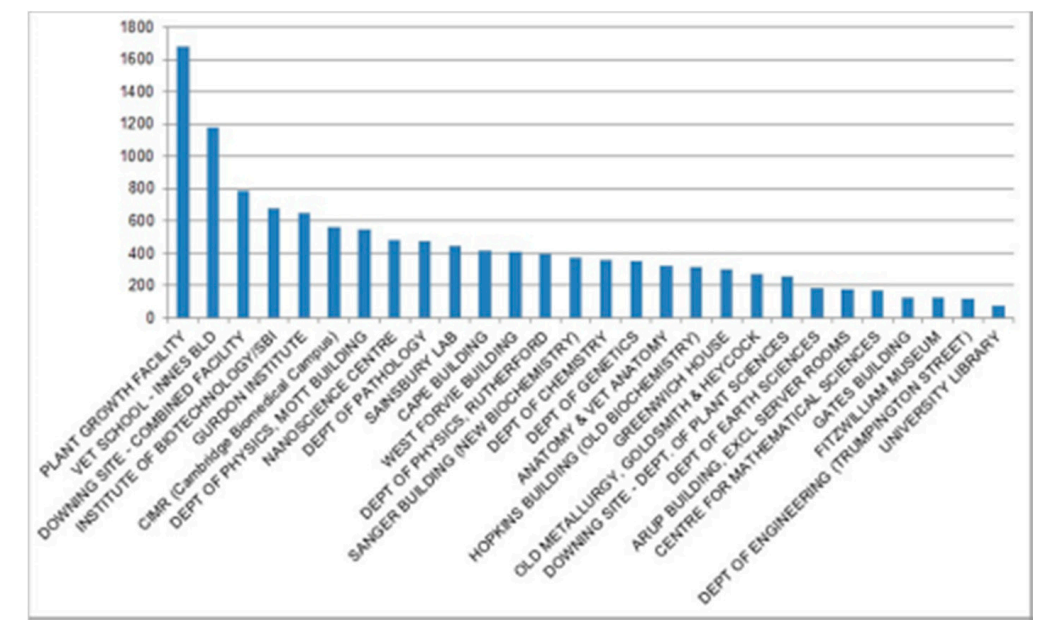

Figure A1. Top 30 users of electricity, ranked by usage per $\mathrm{kWh} / \mathrm{m}^{2}$ (Environment and Energy Office 2016).

The University of Cambridge has also observed performance gap issues; for example, regulated electricity and gas consumptions for Sainsbury Lab at the university are around 130\% and $284 \%$ of the design estimates, respectively. Solar photovoltaic (PV) panels have provided energy as predicted, but only equivalent to $50 \%$ of the $10 \%$ reduction required by the Merton Rule. High occupancy rates outside core office hours have been reported as a major issue affecting energy performance. Thermal comfort is also an issue, as accounts of high temperatures have been noted in some offices. More individual controls over the environment has been suggested as a solution 
to improve thermal comfort (Lee 2014; Khatami et al., 2014). According to the university's policies on thermal comfort, air conditioning should only be allowed for specific academic needs assuming that "occupants will moderate their own comfort by dressing appropriately for their preference" (University of Cambridge 2016).

\section{Appendix B}
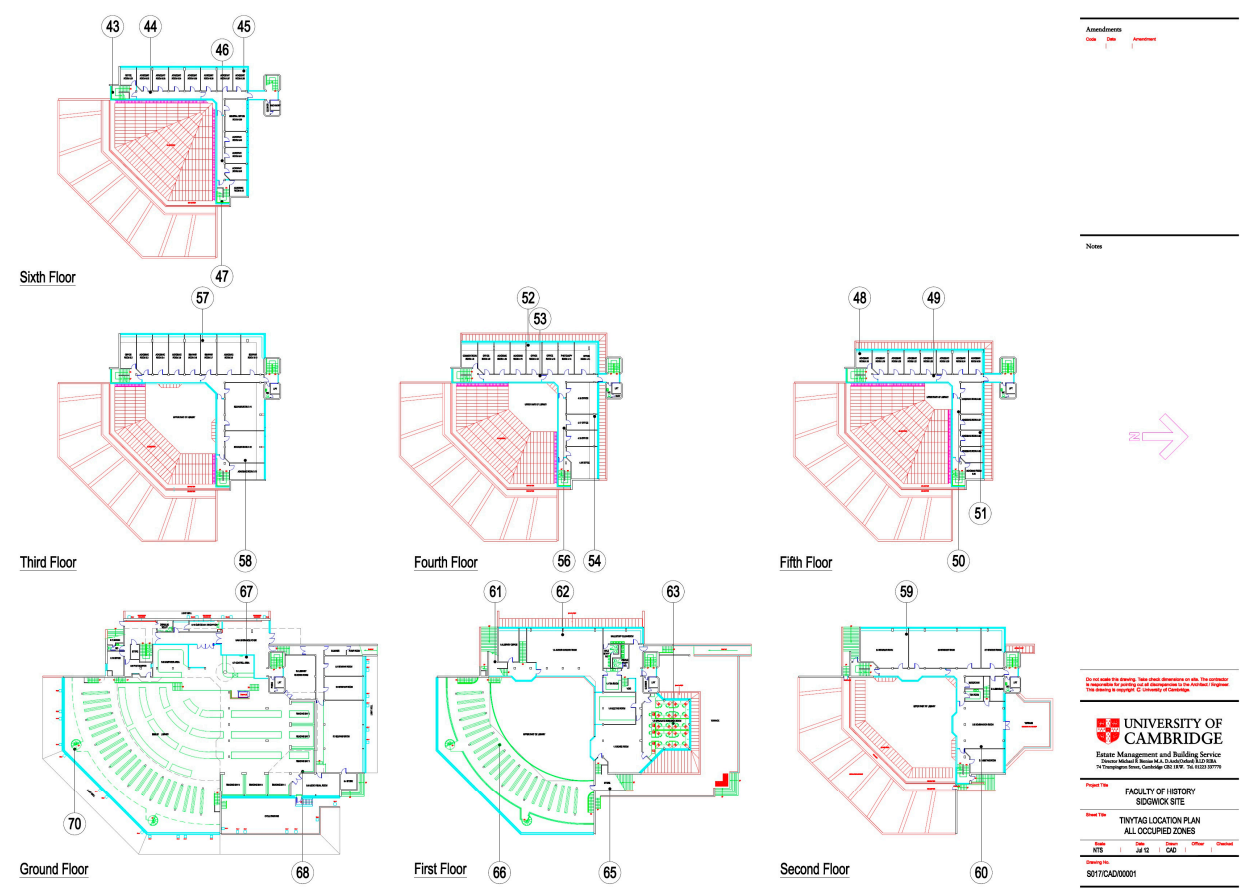

Figure A2. Locations of temperature loggers in History Building (numbered 43-67).

\section{References}

1. Department of Energy \& Climate Change. Energy Consumption in the UK; Department of Energy \& Climate Change: London, UK, 2016.

2. Committee on Climate Change Meeting Carbon Budgets. 2016 Progress Report to Parliament; Committee on Climate Change: London, UK, 2016.

3. Palmer, J.; Cooper, I.; Tillson, A.-A.; Pope, P.; Armitage, P.; Hughes, M.; Godoy-Shimizu, D. Housing Energy Fact File; Department of Energy and Climate Change: London, UK, 2013.

4. Department of Energy and Climate Change (DECC). The Future of Heating: A Strategic Framework for Low Carbon Heat in the UK; DECC: London, UK, 2012.

5. Mohareb, E.A.; Kennedy, C.A. Scenarios of technology adoption towards low-carbon cities. Energy Policy 2014, 66, 685-693. [CrossRef]

6. Bordass, B.; Cohen, R.; Standeven, M.; Leaman, A. Assessing building performance in use 3: Energy performance of the Probe buildings. Build. Res. Inf. 2001, 29, 114-128. [CrossRef]

7. Van Dronkelaar, C.; Dowson, M.; Spataru, C.; Mumovic, D. A Review of the Regulatory Energy Performance Gap and Its Underlying Causes in Non-domestic Buildings. Front. Mech. Eng. 2016, 1, 1-14. [CrossRef]

8. Carbon Trust Closing the Gap —Lessons Learned on Realising the Potential of Low Carbon Building Design; CTG047; The Carbon Trust: London, UK, 2012.

9. Energy Saving Trust. Disaggregation of the Energy Savings Achieved from Insulation in EESoP 3 and the Energy Efficiency Commitment; Technical Report; Departmetn of Energy and Climate Change: London, UK, 2008.

10. Calì, D.; Osterhage, T.; Streblow, R.; Müller, D. Energy performance gap in refurbished German dwellings: Lesson learned from a field test. Energy Build. 2016, 127, 1146-1158. [CrossRef] 
11. Johnston, D.; Farmer, D.; Johnston, D.; Farmer, D. Bridging the domestic building fabric performance gap Bridging the domestic building fabric performance gap. Build. Res. Inf. 2016, 44, 147-159. [CrossRef]

12. Turner, C.; Frankel, M. Energy Performance of LEED for New Construction Buildings; New Buildings Institute: Vancouver, WA, USA, 2008.

13. Scofield, J.H. Efficacy of LEED-certification in reducing energy consumption and greenhouse gas emission for large New York City office buildings. Energy Build. 2013, 67, 517-524. [CrossRef]

14. Wang, C.; Yan, D.; Jiang, Y. A novel approach for building occupancy simulation. Build. Simul. 2011, 4, 149-167. [CrossRef]

15. Ahn, K.U.; Kim, D.W.; Park, C.S.; de Wilde, P. Predictability of occupant presence and performance gap in building energy simulation. Appl. Energy 2016. [CrossRef]

16. Fritsch, R.; Kohler, A.; Nygård-Ferguson, M.; Scartezzini, J.-L. A stochastic model of user behaviour regarding ventilation. Build. Environ. 1990, 25, 173-181. [CrossRef]

17. De Wilde, P. The gap between predicted and measured energy performance of buildings: A framework for investigation. Autom. Constr. 2014, 41, 40-49. [CrossRef]

18. Banham, R. History Faculty, Cambridge. Archit. Rev. 1968, 144, 328-341.

19. Klein, S.A.; Beckman, W.A.; Mitchell, J.W.; Duffie, J.A.; Freeman, T.L.; Mitchell, J.C.; Braun, J.E. TRNSYS 17: A Transient System Simulation Program: Mathematical Reference; University of Wisconsin: Madison, WI, USA, 2009.

20. Neymark, J.; Judkoff, R. Building Energy Simulation Test and Diagnostic Method for Heating, Ventilation, Air Conditioning Equipment Models; National Renewable Energy Lab.: Golden, CO, USA, 2004.

21. TRNSYS. TRNSYS 17: A Transient System Simulation Program-Weather Data; Solar Energy Laboratory, University of Wisconsin: Madison, WI, USA, 2010.

22. Tuohy, P.G.; Murphy, G.B. Closing the gap in building performance: Learning from BIM benchmark industries. Archit. Sci. Rev. 2014, 58, 47-56. [CrossRef]

23. Chartered Institution of Building Services Engineers (CIBSE). Guide A: Environmental Design; CIBSE: London, $\mathrm{UK}, 2015$.

24. Nicol, F.; Humphreys, M. Maximum temperatures in European office buildings to avoid heat discomfort. Sol. Energy 2007, 81, 295-304. [CrossRef]

25. Sunikka-Blank, M.; Galvin, R. Introducing the prebound effect: The gap between performance and actual energy consumption. Build. Res. Inf. 2012, 40, 260-273. [CrossRef]

26. Schwartz, Y.; Raslan, R. Variations in results of building energy simulation tools, and their impact on BREEAM and LEED ratings: A case study. Energy Build. 2013, 62, 350-359. [CrossRef]

27. Baker, P. In situe U-Value Measurements in Traditional Buildings-Preliminary Results. In Historic Scotland Technical Paper 2; Historic Scotland: Edinburgh, UK, 2008.

28. Rye, C.; Scott, C. The SPAB Research Report 1: U-Value Report; Society for the Protection of Ancient Buildings: London, UK, 2012.

29. Robinson, J.F.; Foxon, T.J.; Taylor, P.G. Performance gap analysis case study of a non-domestic building. Proc. Inst. Civ. Eng. Eng. Sustain. 2016, 169, 31-38. [CrossRef]

30. Menezes, A.C.; Cripps, A.; Bouchlaghem, D.; Buswell, R. Predicted vs. actual energy performance of non-domestic buildings: Using post-occupancy evaluation data to reduce the performance gap. Appl. Energy 2012, 97, 355-364. [CrossRef]

31. Haldi, F.; Robinson, D. On the behaviour and adaptation of office occupants. Build. Environ. 2008, 43, 2163-2177. [CrossRef]

32. Fedoruk, L.E.; Cole, R.J.; Robinson, J.B.; Cayuela, A. Learning from failure: Understanding the anticipated-achieved building energy performance gap. Build. Res. Inf. 2015, 1-15. [CrossRef]

33. Mollaoglu-Korkmaz, S.; Swarup, L.; Riley, D. Delivering sustainable, high-performance buildings: Influence of project delivery methods on integration and project outcomes. J. Manag. Eng. 2013, 29, 71-78. [CrossRef]

(c) 2017 by the authors. Licensee MDPI, Basel, Switzerland. This article is an open access article distributed under the terms and conditions of the Creative Commons Attribution (CC BY) license (http:/ / creativecommons.org/licenses/by/4.0/). 